\title{
Critical Success Factors for the Implementation and Adoption of Cloud Services in SMEs
}

\author{
Raoul Hentschel \\ Technische Universität Dresden \\ Chair of Information Systems \\ raoul.hentschel@tu-dresden.de
}

\author{
Christian Leyh \\ Technische Universität Dresden \\ Chair of Information Systems \\ christian.leyh@tu-dresden.de
}

\author{
Teresa Baumhauer \\ Technische Universität Dresden \\ Chair of Information Systems \\ teresa.baumhauer@mailbox.tu- \\ dresden.de
}

\begin{abstract}
Cloud computing (CC) is a fast-growing technology and one of the most important technological drivers of the digitalization of enterprises. The implementation and adoption of a suitable cloud service is challenging and knowledge-intensive and requires strong participation and ownership of business managers and IT units. However, even if the awareness of critical success factors (CSFS) for cloud implementation projects strongly supports avoiding failures within the projects, this field has rarely been researched, especially with a focus on small and medium-sized enterprises (SMEs). Therefore, our paper's contribution to research and practice is the identification of 26 CSFs through a rigorous literature review in combination with an interview study among German SMEs. As a result, we derive a comprehensive model as a starting point for cloud implementation projects in which we assign the CSFs to the respective parties involved in those projects.
\end{abstract}

\section{Motivation}

Cloud computing (CC) has a significant impact on information and communication technology (ICT) and is one of the most important technological drivers of the digitalization of enterprises. An increasing number of organizations are outsourcing data, applications or entire parts of the company's IT to the cloud to achieve financial and technical benefits [35]. Many organizations are moving to $\mathrm{CC}$ because it offers dynamic and scalable resources using internet-based services [34]. However, due to the increasing proliferation of $\mathrm{CC}$ technologies and the growing number of cloud service providers (CSPs), the uncertainty and risks in adopting cloud services have also increased. In addition, the selection and implementation process of suitable cloud services is challenging and knowledge-intensive and requires strong participation and ownership of business managers and IT units [44].
However, CC provides companies of all sizes advantages by this new way of consuming computing resources, such as low/minimal entry costs, pay-asyou-go mode, and great flexibility and scalability [9]. Despite the flexibility cloud services can offer in general, European companies have a different perception when evaluating cloud service adoption. Small and medium-sized enterprises (SMEs) rarely exploit the potentials of CC. A survey conducted in 2016 shows that only $20 \%$ of all SMEs in the EU-28 countries are using cloud services. In contrast, $45 \%$ of large companies are already using cloud services [8].

Without the need to acquire capital-intensive software and hardware and with an additional reduction of operating costs, $\mathrm{CC}$ brings about a dramatic increase in flexibility and responsiveness to change. Therefore, $\mathrm{CC}$ adoption enables SMEs to use modern IT solutions without investing heavily in development and other resources [22].

However, projects to implement new systems and/or technology within a company are always complex as well as time-consuming, and in this process, companies face also enormous risks. To avoid the failure of IT implementation projects, it is essential to be aware of the factors that influence a successful implementation in advance [11, 25, 31]. Considering these so-called critical success factors (CSFs) is of high importance whenever a new system or a new technology is to be adopted and implemented or a current system needs to be upgraded or replaced. Being aware of these factors, a company can positively influence the success of the implementation project and effectively minimize the project's risks.

Therefore, the objective of this paper is to identify CSFs for the implementation of cloud services in SMEs from the user company perspective. As the first step of our study, we conducted a systematic literature review to identify CSFs for cloud implementation projects. On the basis of those CSFs, we conducted multiple interviews within German SMEs (due to our cultural background) that have already implemented cloud solutions. Overall, our study was driven by the following research questions: 
RQ1: Which critical success factors that influence the implementation and adoption of cloud services are discussed in the literature?

RQ2: Which specific critical success factors influence the implementation and adoption of cloud services in German SMEs from the user's perspective?

To answer these research questions, the paper is organized as follows. In section 2, we introduce a short theoretical background on CC as well as CSFs. Section 3 shows the results of our literature review. In section 4 , our data collection methodology of the interview study is described before the results of the interviews are presented. A discussion is presented in section 5 . Finally, a summary of the findings, a conclusion, and an outlook for further research as well implications to practice and research wrap up the study.

\section{Conceptual background}

\subsection{Cloud computing}

As a new possibility for IT sourcing, CC allows companies to gain access to a shared pool of managed and scalable IT resources on a rental basis (e.g., payper-use, pay-per-period). The resources (e.g., networks, servers, storage, applications, services) are offered in a scalable way via the internet without the need for any long-term capital expenditures or specific IT knowledge on the part of the customer [10, 42, 45]. CC represents a transformational shift in IT that is rapidly changing the way in which organizations manage and deliver IT services over the internet. CC enables ubiquitous, on-demand network access to a shared pool of managed IT resources. Researchers have broadly adopted the CC definition of the National Institute of Standards and Technology (NIST), which specifies five essential characteristics (on-demand selfservice, broad network access, resource pooling, rapid elasticity, and measured service), three service models (Software-as-a-Service [SaaS], Platform-as-a-Service [PaaS], and Infrastructure-as-a-Service [IaaS]), and four CC deployment models (private, public, community, and hybrid) [21]. Especially in the IT departments of large organizations, $\mathrm{CC}$ has become an everyday phenomenon $[12,13,40]$.

\subsection{Critical success factors}

The core idea of success factor research is that the success or failure of a company or project can be explained by a few central influencing factors, the socalled critical success factors (CSFs). However, since its beginnings in the $1960 \mathrm{~s}$, research focusing on CSFs has developed continuously. Despite the critique addressed toward CSF research [14], CSFs are addressed and considered in various application domains. In the domain of project management, CSFs are seen as input factors that contribute directly or indirectly to project success [1]. In the area of planning and development of information systems, the CSF approach is also used to adapt system development to the requirements of the company [2]. The implementation of information systems is also dealt with in success factor research. Manifold studies have been published dealing with CSFs when implementing ERP or SCM systems [3, 17, 26]. In spite of many existing CSF definitions $[6,15,30,37]$ all agree that CSFs are of crucial importance for a company or a project. In addition, practical recommendations for the management of a company can be derived by applying the respective CSFs of the application domain [14].

\section{Systematic literature review}

\subsection{Search approach}

To identify relevant literature addressing critical success factors regarding the implementation and adoption of cloud services, we applied a systematic literature review. Following the approach of [43] we defined as sources for our initial search the databases AIS Electronic Library (AISel), Business Source Complete (ebsco), ScienceDirect, and SpringerLink. To cover a broad set of publications, we searched each database with the search string (derived from the focus of our review in combination with a first screening of selected relevant publications) in title, abstract and keywords (see Figure 1). In addition, the proceedings of the Hawaii International Conference on System Sciences (HICSS) were initially screened based on content with the search terms ${ }^{*} \mathrm{Cloud}^{*}$ or ${ }^{*} \mathrm{aaS} *$ and then manually checked for relevance. The search in Business Source Complete was limited to peerreviewed publications and the search in ScienceDirect to the fields of business, management and accounting and computer science. In all databases, we addressed only papers in German or English.

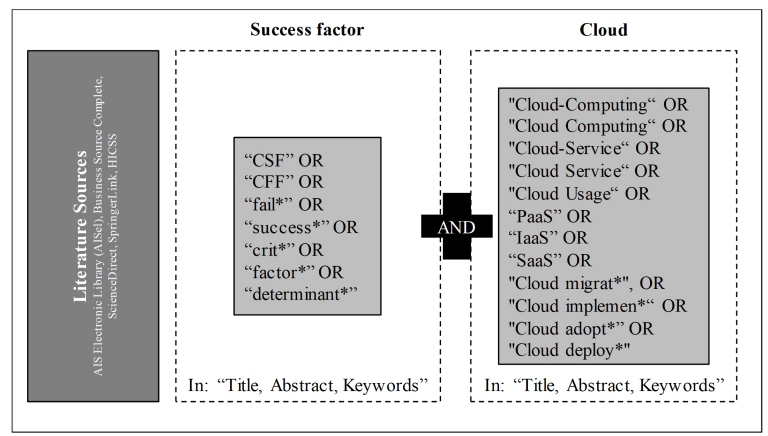

Figure 1: Search terms used in databases. 
Figure 2 provides an overview of the different steps and results in terms of numbers regarding our literature review. Searching the four databases using the previously defined search terms, we identified 2,902 publications (steps $1 \& 2$ ). After the exclusion of duplicates, 2,490 publications remained (step 3). In a final step, a detailed analysis of the remaining articles was conducted. Among these, a preselection was made based on title and abstract or, if necessary, by a short review of the full text (step 4). In this step, all three authors independently checked the relevancy of each article by analyzing title, abstract, and keywords with the focus of our research questions. To compare the results, the remaining papers from the preselection of each author were discussed among all authors. In total, in step 4 the number of publications from the databases was reduced to 73 . In addition, 15 potentially relevant publications from the HICSS were identified based on the title. A backwards search among the remaining results of the databases resulted in another 13 highly cited publications. A supplementary search provided two additional sources for further consideration.

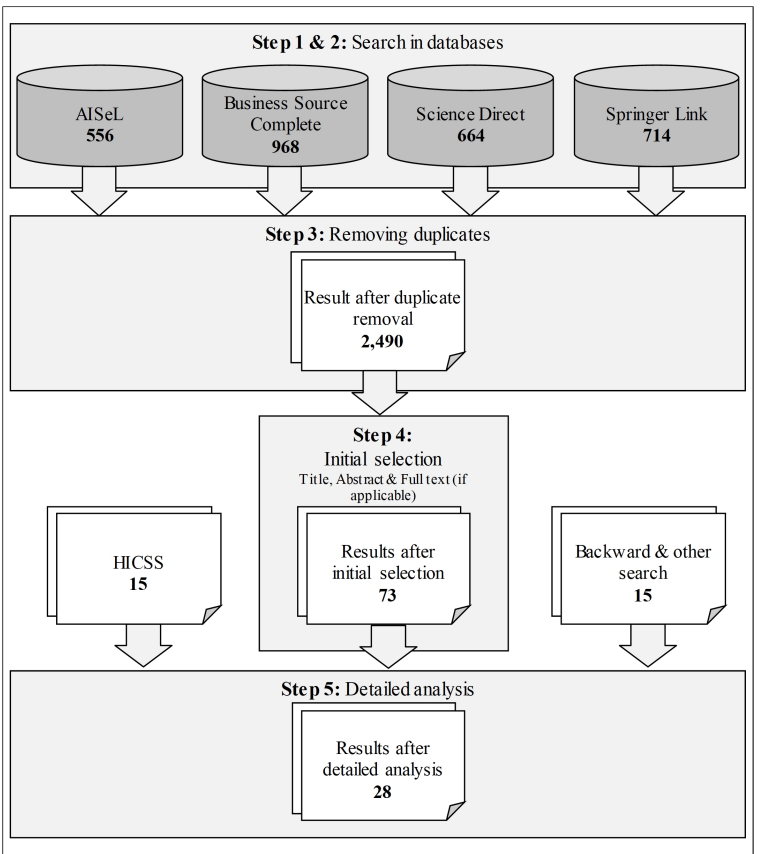

Figure 2: Steps of the literature review.

In step 5, again, all three authors independently assessed each article and discussed the results afterwards. The aim of this step was to identify those papers that actually deal with CSFs for the implementation and adoption of cloud services. Therefore, the papers were searched manually for CSFs by each author separately. The relevance of the papers was assessed according to the focus of our research questions. Only papers that have at least one of the following foci remained for further detailed analysis: (1) concrete CSFs are explicitly pointed out and are the focus of the paper's investigation; (2) CSFs are explicitly pointed out but are not the focus of the paper's investigation; (3) CSFs are not explicitly mentioned but indirectly conclusions are made concerning CSFs. After this detailed analysis and discussion among the authors, 28 relevant papers remained and the CSFs were identified.

\subsection{Review results}

With only 28 papers dealing with cloud project CSFs it can be stated that this research field is underrepresented. Compared to other CSF literature reviews (e.g., 320 papers dealing with ERP project CSFs [17]) the cloud literature has only marginally dealt with CSFs. All 28 papers were published between the years 2011 and 2017, most of them between 2013 and 2015. Regarding the research approach chosen, the papers consisted of 3 single- or multiple-case studies, 8 surveys and 17 non-empirical approaches (e.g., articles where CSFs were derived from chosen literature).

From the identified 28 papers, we could derive 26 CSFs affecting cloud implementation projects. Figure 3 presents an overview of the frequency of the $26 \mathrm{CSF}$ mentioned in the literature. However, only the most important and subsequently discussed factors are described. The description of all 26 CSFs can be requested from the authors.

Information security, data privacy, and compliance: Compliance and the aspects of security and data protection during the implementation and usage of cloud solutions are the most frequently mentioned CSFs. Ensuring security in a cloud system is a success factor both during development and during implementation. Compliance is intended to ensure that the company's actions do not violate laws, social values or internal regulations [39]. In the field of CC, compliance means the legally compliant use of the technology. IT security and data protection are two core aspects, which must be taken into account in the context of corporate compliance. IT security includes various measures to prevent unauthorized access and loss of data. These measures can be of an organizational, personnel or technical nature. Preventive measures to ensure IT security are taken both by the CSP (e.g., by security concept) and by the cloud user [24]. The aspect of data protection includes the protection of personal data. The location of the data center is important in order to meet country-specific data protection requirements [24]. Security concerns are often addressed by choosing the private cloud as the delivery model [20]. 
Vendor relationship and support: Close cooperation and support from an experienced CSP is a critical factor, especially for inexperienced companies, to successfully introduce a cloud service [41]. Future cooperation with the CSP must be focused at the selection process [36]. Regular meetings are held from the start to ensure that the systems that have been implemented actually meet the requirements and are deployed in a low-risk environment [23]. In addition, trust in the CSP to ensure continuous operation and support is also considered a critical success factor and essential component of the CSP relationship [29].

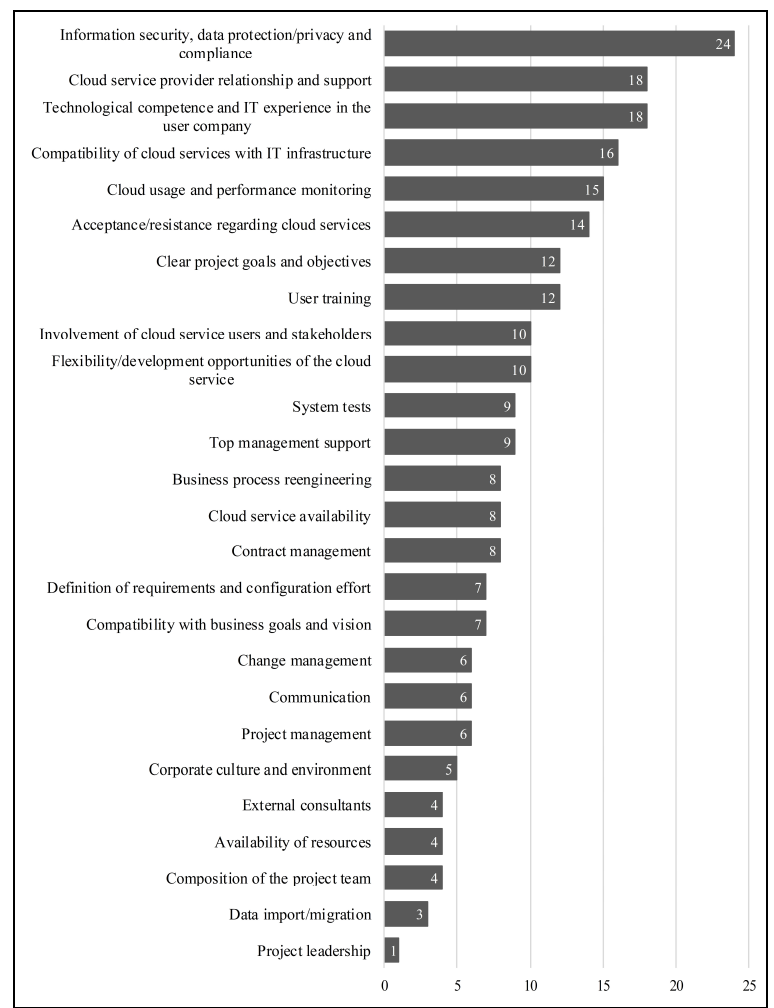

Figure 3: Result of the systematic literature review CSFs ordered by frequency.

Technological competence and IT experience in companies: Technological competence in the company is just as important as the factor Vendor relationship and support for the successful implementation and adoption of cloud services [36]. Technology competence includes various physical components (e.g., computers), on the one hand, but also the IT specialists in the company. These two aspects constitute the platform on which cloud applications are built [4]. The general IT experience of employees and their knowledge of cloud services contribute to the successful implementation of a cloud solution. As the IT resources become more advanced, it becomes easier to implement a cloud solution in the organization [33].
Compatibility of cloud services with IT infrastructure: Another factor for cloud implementation projects is their compatibility with the company's existing and future IT infrastructure. A cloud service that is compatible with the existing infrastructure leads to fewer customizations needing to be made during implementation. Thus, compatibility must be addressed when selecting cloud services. In the early phase of deployment, possible errors and malfunctions should be localized and, if necessary, adjusted. This ensures the seamless integration of new applications into the IT landscape [24]. Data portability is also a critical factor for companies when using cloud services, as it reduces dependence on the CSP and thus lessens the lock-in effect [32].

Cloud usage and performance monitoring: To ensure the continuous success of the cloud solution and reveal any necessary changes, it is necessary to monitor performance and costs [24, 41]. If usageoriented price models (pay-per-use) are used, the actual usage intensity should be monitored by various tools. This ensures that the costs of cloud usage remain within budget. The measurement can be performed by newly developed components or special tools that are provided by the CSP $[7,29]$.

\section{Interview study}

\subsection{Study design}

To investigate the possible relevance of the identified factors for SMEs and to possibly identify further CSFs that have not been identified in other research so far, we conducted an interview study. Our interview study (as step 2 in this study) follows an exploratory research design to validate the success factors identified in the literature by comparing them with the experience of practitioners. We decided to employ a qualitative approach that considers the personal perceptions, motives, background, and experience of the experts in a more comprehensive and detailed way compared to a quantitative approach [27]. To ensure comparability of interview results, the interviews were conducted using semi-structured interview guidelines. The success factors identified in the literature were a basis for the interview guideline. Therefore, the 26 identified success factors were thematically divided into four different categories: aspects of project organization, organizational aspects, company-related aspects and technological aspects. Table 1 shows the 26 success factors as assigned to the four categories.

For this study, German SMEs that have already implemented cloud solutions and have therefore gained experience in the field of research were identified. 
Based on their experience, these user companies can provide relevant information that is important for the implementation and operation of a cloud service. For the empirical study, employees of user companies were interviewed who either directed or were involved in the project to implement a cloud solution. We were able to conduct interviews with eleven experts. Table 2 provides an overview of the interviewed companies and the position of the interview partners.

Table 1: Assignment of the success factors.

\begin{tabular}{|l|l|}
\hline Category & Success Factor \\
\hline $\begin{array}{l}\text { Aspects of } \\
\text { project } \\
\text { organization }\end{array}$ & $\begin{array}{l}\text { - Clear project goals and objectives } \\
\text { - Project management } \\
\text { - Composition of the project team } \\
\text { - Project leadership } \\
\text { - Availability of resources } \\
\text { - Involvement of cloud service users and } \\
\text { stakeholders } \\
\text { - User training } \\
\text { - System tests } \\
\text { - Cloud service provider relationship and } \\
\text { support } \\
\text { - External consultants }\end{array}$ \\
\hline $\begin{array}{l}\text { Organizational } \\
\text { aspects }\end{array}$ & $\begin{array}{l}\text { - Top management support } \\
\text { - Corporate culture and environment } \\
\text { - Acceptance/resistance regarding cloud } \\
\text { - Change management } \\
\text { - Communication }\end{array}$ \\
\hline $\begin{array}{l}\text { Company- } \\
\text { related aspects }\end{array}$ & $\begin{array}{l}\text { - Business process reengineering } \\
\text { - Compatibility with business goals and vision } \\
\text { - Technological competence and IT experience } \\
\text { in the user company }\end{array}$ \\
\hline $\begin{array}{l}\text { Technological } \\
\text { aspects }\end{array}$ & $\begin{array}{l}\text { - Definition of requirements and configuration } \\
\text { effort } \\
\text { - Compatibility of cloud services with IT } \\
\text { infrastructure } \\
\text { - Data import/migration } \\
\text { - Flexibility/development opportunities of the } \\
\text { cloud service } \\
\text { - Information security, data protection/privacy } \\
\text { and compliance } \\
\text { - Cloud usage and performance monitoring } \\
\text { - Coutract management }\end{array}$ \\
\hline
\end{tabular}

The eleven interviews were conducted between September 13 and October 5, 2017. Nine interviews were conducted by phone, while the other two were organized as face-to-face interviews. The duration of the interviews ranged from 40 to 50 minutes.

\subsection{Data analysis}

The data analysis was done based on qualitative content analysis that enables systematic analysis by processing the material step by step with theory-based category systems [19].
Table 2: Overview of interview partners

\begin{tabular}{|c|c|c|c|}
\hline 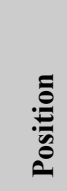 & 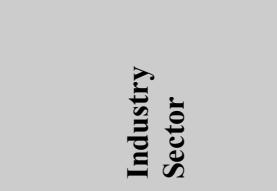 & 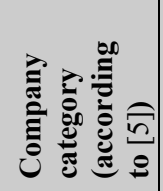 & 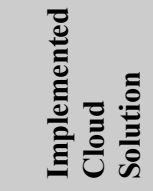 \\
\hline $\mathrm{MD}$ & $\begin{array}{l}\text { Training of audit } \\
\text { personnel }\end{array}$ & $\begin{array}{l}\text { Micro- } \\
\text { enterprise }\end{array}$ & SaaS, public \\
\hline IT & Financial Services & $\begin{array}{l}\text { Medium } \\
\text { enterprise }\end{array}$ & SaaS, public \\
\hline $\mathrm{DM}$ & $\begin{array}{l}\text { Personnel marketing, } \\
\text { recruiting and personnel } \\
\text { procurement }\end{array}$ & $\begin{array}{l}\text { Small } \\
\text { enterprise }\end{array}$ & $\begin{array}{l}\text { SaaS, public } \\
\text { IaaS, private } \\
\text { PaaS, public }\end{array}$ \\
\hline $\mathrm{MD}$ & Online marketing & $\begin{array}{l}\text { Micro- } \\
\text { enterprise }\end{array}$ & SaaS, public \\
\hline MD & Visual communication & $\begin{array}{l}\text { Micro- } \\
\text { enterprise }\end{array}$ & $\begin{array}{l}\text { SaaS, public } \\
\text { IaaS, private }\end{array}$ \\
\hline $\mathrm{MD}$ & Real estate industry & $\begin{array}{l}\text { Micro- } \\
\text { enterprise }\end{array}$ & SaaS, public \\
\hline $\mathrm{MD}$ & Printing industry & $\begin{array}{l}\text { Micro- } \\
\text { enterprise }\end{array}$ & SaaS, public \\
\hline $\mathrm{MD}$ & Rental and trade of RVs & $\begin{array}{l}\text { Micro- } \\
\text { enterprise }\end{array}$ & SaaS, public \\
\hline MD & Renewable energy & $\begin{array}{l}\text { Micro- } \\
\text { enterprise }\end{array}$ & IaaS, private \\
\hline $\mathrm{MD}$ & $\begin{array}{l}\text { Removals and special } \\
\text { transportation }\end{array}$ & $\begin{array}{l}\text { Small } \\
\text { enterprise }\end{array}$ & IaaS, private \\
\hline MD & $\begin{array}{l}\text { Management } \\
\text { consultancy }\end{array}$ & $\begin{array}{l}\text { Micro- } \\
\text { enterprise }\end{array}$ & SaaS, public \\
\hline \multicolumn{4}{|c|}{$\begin{array}{l}\text { MD - Managing director; DM - Department manager; IT - IT } \\
\text { manager }\end{array}$} \\
\hline
\end{tabular}

Therefore, the interviews were recorded on a smartphone and were transcribed afterwards. The text material prepared based on the interviews and provided in the form of transcripts was initially reduced to its core statements for this research project. This was using the data analysis software MAXQDA (release 12.2.1). Thereafter, the core statements were matched to the initial four categories. In addition to the qualitative content analysis, the individual factors were evaluated based on the statements made by the interviewees. This was done using a three-level scale, which we have used in similar CSF-related interview studies, such as for ERP implementation projects [16] or SCM implementation projects [18]. This allows a ranking of the identified CSFs. The statements of the interviewees were assigned the ratings important and less important, each with a score of two, one or zero points. CSFs rated as "important" were characterized by statements like "that was completely important for us" or "that was essential". Factors that were mentioned as the biggest challenges or most important success factors also received the ranking important. Individual success factors that the interviewees had a neutral attitude to or were as described in the literature were assigned a neutral rating. 
Table 3: Categorization and ranking of success factors (model adapted from $[\mathbf{2 8}, \mathbf{3 8}]$ ).

\begin{tabular}{|c|c|c|c|c|c|c|}
\hline & \multicolumn{3}{|l|}{ Strategic } & \multicolumn{3}{|l|}{ Tactical } \\
\hline & Critical Success Factors & Rank & $\begin{array}{l}\text { Factor } \\
\text { rating* }\end{array}$ & Critical Success Factors & Rank & $\begin{array}{l}\text { Factor } \\
\text { rating* }\end{array}$ \\
\hline \multirow{12}{*}{ 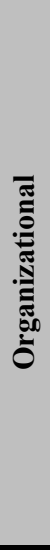 } & Corporate culture and environment & 2 & 19 & $\begin{array}{l}\text { Technological competence and IT experience } \\
\text { in the user company }\end{array}$ & 15 & 10 \\
\hline & $\begin{array}{l}\text { Compatibility with business goals and } \\
\text { vision }\end{array}$ & 4 & 17 & User training & 17 & 9 \\
\hline & Top management support & 6 & 16 & Communication & 22 & 6 \\
\hline & Business process reengineering & 6 & 16 & Project management & 25 & 5 \\
\hline & $\begin{array}{l}\text { Acceptance/resistance regarding cloud } \\
\text { services }\end{array}$ & 8 & 14 & External consultants & 26 & 4 \\
\hline & Clear project goals and objectives & 10 & 13 & & & \\
\hline & Project leadership & 13 & 12 & & & \\
\hline & $\begin{array}{l}\text { Cloud service provider relationship and } \\
\text { support }\end{array}$ & 13 & 12 & & & \\
\hline & Availability of resources & 15 & 10 & & & \\
\hline & Change management & 19 & 7 & & & \\
\hline & Composition of the project team & 22 & 6 & & & \\
\hline & $\begin{array}{l}\text { Involvement of cloud service users and } \\
\text { stakeholders }\end{array}$ & 22 & 6 & & & \\
\hline \multirow{5}{*}{ 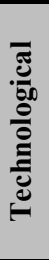 } & $\begin{array}{l}\text { Information security, data } \\
\text { protection/privacy and compliance }\end{array}$ & 4 & 17 & $\begin{array}{l}\text { Definition of requirements and configuration } \\
\text { effort }\end{array}$ & 1 & 21 \\
\hline & $\begin{array}{l}\text { Flexibility/development opportunities } \\
\text { of the cloud service }\end{array}$ & 10 & 13 & Cloud service availability & 3 & 18 \\
\hline & $\begin{array}{l}\text { Cloud usage and performance } \\
\text { monitoring }\end{array}$ & 19 & 7 & $\begin{array}{l}\text { Compatibility of cloud services with IT } \\
\text { infrastructure }\end{array}$ & 8 & 14 \\
\hline & Contract management & 19 & 7 & System tests & 10 & 13 \\
\hline & & & & Data import/migration & 17 & 9 \\
\hline
\end{tabular}

Factors which interviewees described as "not relevant" or "does not matter" were interpreted as less important. The total number of assigned scores, based on the evaluation of the interviews, resulted in an overall score for each success factor. This resulted in a ranking of the CSFs, which can be interpreted as their relative importance. The most important factor is the success factor with the highest rating.

\subsection{Results of the interview study}

Through the qualitative content analysis, the statements of the interview partners were assigned to the individual CSFs. Each of the 26 success factors that were identified in the literature was mentioned by at least one interviewee. In addition, the interviews did not identify any other new success factors.

The individual factors were further categorized using a matrix with the dimensions strategically and tactically as well as organizationally and technologically according to $[28,38]$. Table 3 shows the corresponding matrix and assigns the $26 \mathrm{CSFs}$.

The strategic perspective includes business core competencies that support the long-term achievement. The tactical perspective describes business activities with short-term objectives. The organizational dimension covers various organizational aspects that are relevant in the context of implementation and usage. Technical aspects depending on the selected cloud solution are discussed from a technological perspective [28, 38].

The five most important factors that, according to the empirical study, contributed most to the successful implementation and adoption of a cloud solution in SMEs are these:

- Definition of requirements and configuration effort

- Corporate culture and environment

- System availability

- Compatibility with business goals

- Information security, data privacy and compliance.

However, if we consider the factors that can be found in the lower part of the ranking, it becomes apparent that external consultants are less important for the SMEs interviewed. Comprehensive project management, as described in the literature, also plays a minor part from the perspective of the interview partners. In addition, these factors are also in the lower evaluation segment:

- Communication

- Stakeholder and system user involvement

- Project team composition

- Contract management

- Monitoring of cloud service and performance 


\section{- Change management}

The analysis shows that most of the aspects relevant to SMEs are organizational factors. Of the twelve most important success factors, $50 \%$ are organizational factors with a strategic orientation. It is also interesting to mention that two of the top three factors belong to the category of technological factors with a tactical orientation. On the other hand, no organizational success factor with a tactical orientation can be found among the twelve most important factors.

\section{Discussion}

\subsection{Characteristics of the CSFs}

A comparison of the 26 identified success factors from the literature and the factors considered in the cloud projects of the SMEs interviewed indicates that twelve of the factors considered in the cloud projects were as described in the literature. For the other 14 CSFs, there were some differences regarding their characteristics:

The factor Information security, data protection and compliance was not as strong in most companies as they should have been according to the literature analyzed. The subject of compliance was described by most interviewees as unimportant for SMEs. In addition, measures to ensure IT security have not been implemented in most companies to the extent required by the literature. Regarding data privacy policies, companies had different perspectives. Some attached great importance to it and have taken measures that are also recommended in the literature (e.g., private cloud as delivery model). On the other hand, some interviewees stated that they were aware of the risks but did not see any need to introduce specific actions to increase privacy.

The success factor of Technological competence and IT experience in the company was also described differently in the companies interviewed than in the literature. A high level of technological competence was not necessarily a requirement for a successful cloud service implementation. The solutions used were often described as simple and intuitive that no extensive IT experience or IT specialists were required.

Regarding the factor Compatibility of cloud services within the IT infrastructure, the interviewees stated, in contrast to the literature, that the portability of the data was not important for their company and that the lock-in effect was also not addressed.

According to the literature, the User training factor also includes the execution of workshops. This was only confirmed by some of the interviewees. In many cases, the training was provided using materials provided by the CSP or no training of the system users was necessary at all. If necessary, ad hoc meetings were held in which any problems were solved.

The Involvement of stakeholders and system users was only considered relevant for the successful implementation and adoption by some of the interviewees. In some cases, stakeholders and system users were not involved in advance, as this was not considered necessary due to the awareness of the chosen cloud service.

In addition, the important factor Flexibility/ development possibilities of the cloud service could not be fully confirmed by most interviewees. The use of third-party solutions and standardized programming interfaces did not play a role in any of the companies interviewed.

There were significant differences regarding $T o p$ management support. In many of the companies interviewed, the managing director was both initiator and manager of the cloud implementation project. However, some interviewees reported that the management was aware of the project but was neither actively involved in the project nor thought it necessary to motivate the employees. Hence, this low involvement of the management was not perceived as negative by the interviewees.

The optimization of business processes played a major role in most companies, as has also been explained in the literature on the factor Business process reengineering. However, it became apparent that only individual processes were changed and adapted to the new cloud solution as part of business process optimization.

The demanding Contract management in cloud computing was confirmed by very few interview partners, as the literature indicates. Most solutions implemented by the interviewees' companies are standard products which had no scope for drafting contracts with the provider. However, this was not perceived as a disadvantage in any of the cases, because interviewees trusted the providers' professionalism and reliability, so that a specific contract design was not considered necessary.

\subsection{Importance of the CSFs}

To identify the difference between the importance of CSFs for SMEs and the success factors identified in the literature, a comparison of the ranking of the factors was done. Table 4 shows the top five and the bottom five factors from the literature review and the empirical study. According to the systematic literature review, the success factor Information security, data privacy and compliance is the most important factor, as 
this factor has been mentioned most frequently and discussed most intensively in the literature.

Other top-ranked CSFs include Vendor relationship and support, Technological competence and IT experience, Compatibility of cloud services with IT infrastructure, and Monitoring cloud usage and performance. Comparing this with the top five factors resulting from the interview partners' evaluation, the top five success factors also include only Information security, data privacy and compliance. Accordingly, this factor plays an important role in the literature as well as in practice for the successful implementation and adoption of cloud services in SMEs.

The other four factors that are considered important in the literature can be found in the ranking of the empirical study in the middle ranks. Thus, they are relevant to companies to different degrees of importance but are not as important as described in the literature. In addition to the CSF of Information security, data privacy and compliance, the factors of Requirement definition and configuration effort, Corporate culture and environment, System availability and Compatibility with corporate goals are also among the five factors of the interview study.

Further CSFs that were considered unimportant according to the systematic literature review (Availability of resources, Data import/migration, Project managers) are rated more important by the interviewees and are in the middle of the ranking order.

Table 4: Comparison of the top five and bottom five factors.

\begin{tabular}{|c|c|c|}
\hline Rank & Literature review & Interview study \\
\hline 1 & $\begin{array}{l}\text { Information security, data } \\
\text { protection/privacy and } \\
\text { compliance }\end{array}$ & $\begin{array}{l}\text { Definition of } \\
\text { requirements and } \\
\text { configuration effort }\end{array}$ \\
\hline \multirow[t]{2}{*}{2} & $\begin{array}{l}\text { Cloud service provider } \\
\text { relationship and support }\end{array}$ & \multirow[t]{2}{*}{$\begin{array}{l}\text { Corporate culture and } \\
\text { environment }\end{array}$} \\
\hline & $\begin{array}{l}\text { Technological } \\
\text { competence and IT } \\
\text { experience in the user } \\
\text { company }\end{array}$ & \\
\hline 3 & & Cloud service availability \\
\hline \multirow[t]{2}{*}{4} & \multirow{2}{*}{$\begin{array}{l}\text { Compatibility of cloud } \\
\text { services with IT } \\
\text { infrastructure }\end{array}$} & $\begin{array}{l}\text { Compatibility with } \\
\text { business goals and vision }\end{array}$ \\
\hline & & $\begin{array}{l}\text { Information security, data } \\
\text { protection/privacy and } \\
\text { compliance }\end{array}$ \\
\hline 5 & $\begin{array}{l}\text { Cloud usage and } \\
\text { performance monitoring }\end{array}$ & \\
\hline \multirow[t]{3}{*}{22} & External consultants & $\begin{array}{l}\text { Composition of the } \\
\text { project team }\end{array}$ \\
\hline & Availability of resources & $\begin{array}{l}\text { Involvement of cloud } \\
\text { service users and } \\
\text { stakeholders }\end{array}$ \\
\hline & $\begin{array}{l}\text { Composition of the } \\
\text { project team }\end{array}$ & Communication \\
\hline 25 & Data import/migration & Project management \\
\hline 26 & Project leadership & External consultants \\
\hline
\end{tabular}

\subsection{Cloud implementation project model}

Since cloud projects can represent complex and extensive projects, a structured approach for the cloud implementation is mandatory. Therefore, the respective CSFs should also be included in the concrete design of the project's procedure. However, since cloud projects can have different focuses (e.g., cost optimization, high availability), not all factors must be relevant for each company and for each project. The CSFs identified in the literature and interview study are related to and thereby affecting the various parties (e.g., management board, IT department) involved in the cloud project.

To address this aspect, we developed a comprehensive model as a starting point for cloud implementation projects (see Figure 4). As shown, this model has a complex character since various CSFs have to be considered by different parties simultaneously (those CSFs are written bold and in capital letters).

However, there are also CSFs that affect only one party (CSP or User company) or those that do not directly affect the parties but are rather of fundamental nature (shown as an arrow below and boxes in the grey area at the top).

In summary, it must be noted that before and during the implementation of cloud projects, companies should be aware of the effects that this project has on each involved party and which respective CSFs should be taken into consideration or at least kept in mind.

\section{Conclusion and limitations}

The objective of this paper was to identify CSFs for the implementation of cloud services in SMEs from the user company perspective. In summary, our study provides an interesting insight into the mindset regarding cloud services and their implementation and adoption in the surveyed companies. Our study combines different methods and contributes to practice and IS research. From a researcher's point of view, our paper contributes to cloud and CSF research by identifying 26 CSFs derived from a systematic literature review and from an interview study among German SMEs. By answering RQ1 with the literature review, we identified CSFs that are relevant for the implementation and adoption of cloud services and that are only rarely discussed. On this basis, RQ2 was answered by examining those CSFs through an interview study and applying them to the SME context.

For practice/practitioners, our interview study provides insights into cloud implementation projects from the perspective of eleven cloud-user companies.

All identified factors from the literature were confirmed by the interviewees, since concrete 


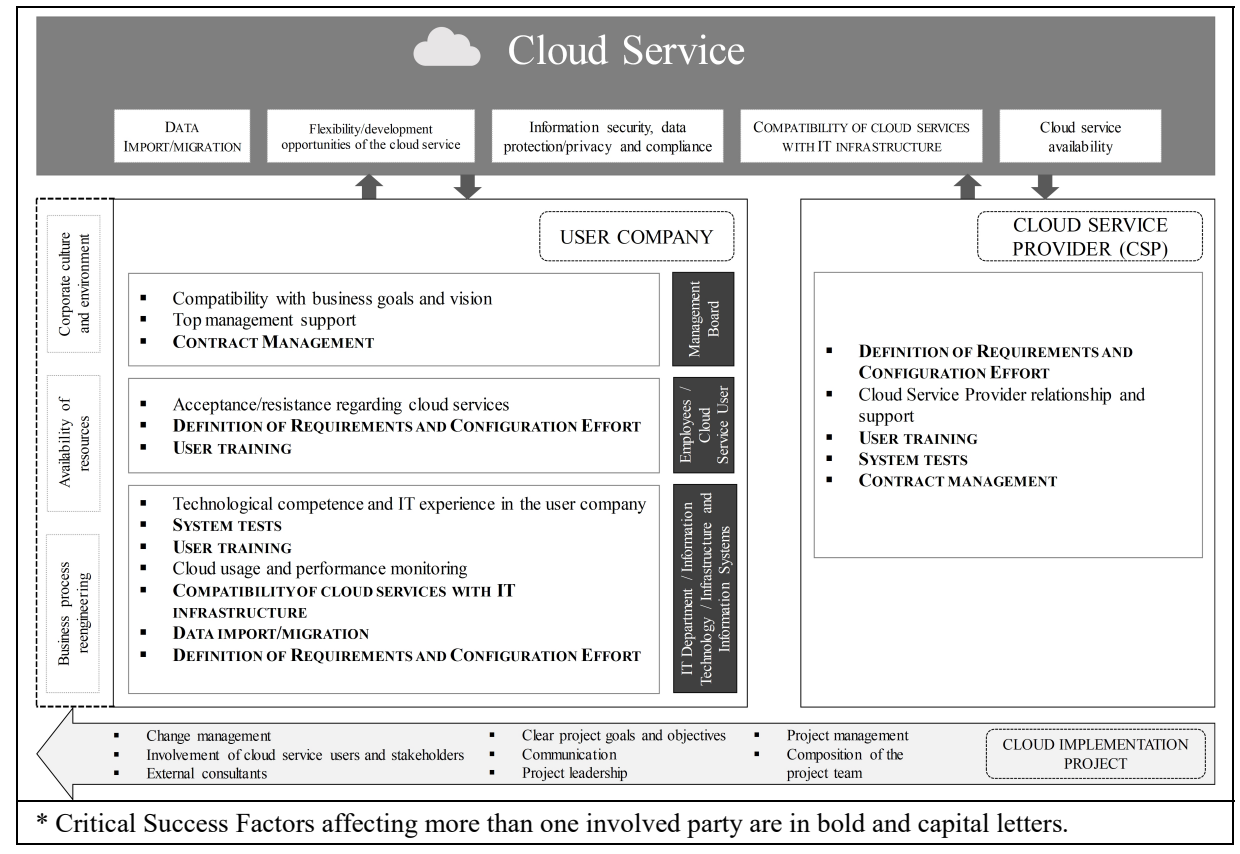

Figure 4: Cloud Implementation Parties' Responsibility for Critical Success Factors.

indications were found for each of the factors in at least one of the interviewed companies. In addition, integrating the CSFs in a cloud implementation project model (Fig 4) can help companies to support their own cloud implementation projects by taken into account the identified CSFs.

A limitation of the paper at hand is its research method. The number and selection of companies is not a representative sample. Therefore, in comparison, no statistically generalizable statements can be made from the results of the study. As most of the enterprises surveyed were micro-enterprises, it is possible that the survey of larger enterprises in the SME category would have resulted in different findings. Also, the evaluation of the interview contents in the context of the empirical investigation as well as the ranking of the factors determined from them may have turned out differently.

However, the use of the qualitative method is highly suitable for this research, as so far only a small amount of scientific research has been conducted in this subject area. Therefore, the chosen approach represents an appropriate methodology for obtaining a preliminary overview of CSFs for the implementation and adoption of cloud services in SMEs.

With a focus on our long-term research, the next step will be based on the results of this study and on the result of a previous study regarding the perspective of CSPs. In the previous study, we investigated which customer requirements and barriers are perceived by CSPs to meet customer requirements [10]. Therefore, the aim of the next step is to determine technical and functional requirements for cloud services from the perspective of different roles (e.g., business department, IT department). Finally, we will develop a cloud service selection and implementation framework as an artifact (in terms of design science research) that can support user companies and CSPs in the adoption of cloud services.

\section{References}

[1] Alias, Z., E.M.A. Zawawi, K. Yusof, and N.M. Aris, "Determining Critical Success Factors of Project Management Practice: A Conceptual Framework", Procedia Social and Behavioral Sciences 153, 2014, pp. 61-69.

[2] Byers, C.R., and D. Blume, "Tying critical success factors to systems development", Information \& Management 26(1), 1994, pp. 51-61.

[3] Denolf, J.M., J.H. Trienekens, P.M. (Nel) Wognum, J.G.A.J. van der Vorst, and S.W.F. (Onno) Omta, "Towards a framework of critical success factors for implementing supply chain information systems", Computers in Industry 68, 2015, pp. 16-26.

[4] Espadanal, M., and T. Oliveira, "Cloud Computing Adoption by Firms", MCIS 2012 Proceedings, (2012).

[5] EU Commission, The new SME definition - User guide and model declaration, European Commission, 2005.

[6] Finney, S., and M. Corbett, "ERP implementation: a compilation and analysis of critical success factors", Business Proc. Mngt. Journal 13(3), 2007, pp. 329-347.

[7] Gholami, M.F., F. Daneshgar, G. Low, and G. Beydoun, "Cloud migration processs", Journal of Systems and Software 120, 2016, pp. 31-69.

[8] Giannakouris, K., and M. Smihly, "Cloud computing statistics on the use by enterprises", 2016. 
http://ec.europa.eu/eurostat/statistics-explained/index.php/ Cloud computing _ statistics on the use by enterprises [9] Hedman, J., and X. Xiao, "Transition to the Cloud: A Vendor Perspective", HICSS 2016 Proceedings, (2016).

[10] Hentschel, R., C. Leyh, and A. Petznick, "Current cloud challenges in Germany: the perspective of cloud service providers", Journal of Cloud Computing 7(1), 2018.

[11] Jones, A., J. Robinson, B. O'Toole, and D. Webb, "Implementing a bespoke supply chain management system to deliver tangible benefits", The Intern. Journal of Advanced Manufacturing Technology 30(9), 2006, pp. 927-937.

[12] Kappelman, L., J. Luftman, E. Mclean, and V. Johnson, "Key Issues of IT Organizations and Their Leadership: The 2013 SIM IT Trends Study", MIS Quarterly Executive 12(4), 2013, pp. 227-240.

[13] Kappelman, L., E. McLean, V. Johnson, et al., "The 2016 SIM IT Trends Study", MIS Quarterly Executive 16(1), 2017, pp. 55-83.

[14] Kieser, A., and A. Nicolai, "Trotz eklatanter Erfolglosigkeit: Die Erfolgsfaktorenforschung weiter auf Erfolgskurs", Die Betriebswirtschaft 62(6), 2002, pp. 579596.

[15] Leidecker, J.K., and A.V. Bruno, "Identifying and using critical success factors", Long Range Planning 17(1), 1984, pp. 23-32.

[16] Leyh, C., "Critical success factors for ERP projects in small and medium-sized enterprises - The perspective of selected German SMEs", FedCSIS 2014 Proc., (2014).

[17] Leyh, C., and P. Sander, "Critical Success Factors for ERP System Implementation Projects: An Update of Literature Reviews", In D. Sedera, N. Gronau and M. Sumner, eds., Enterprise Systems. Strategic, Organizational, and Technological Dimensions. Springer International Publishing, 2015, 45-67.

[18] Leyh, C., and J. Thomschke, "Critical success factors for implementing supply chain management systems - the perspective of selected German enterprises”, FedCSIS 2015 Proceedings, (2015).

[19] Mayring, P., Einführung in die qualitative Sozialforschung, Beltz, Weinheim, Basel, 2002.

[20] McGeough, B., and B. Donnellan, "Factors that affect the adoption of cloud computing for an enterprise.", ECIS 2013 Proceedings, (2013).

[21] Mell, P., and T. Grance, "The NIST definition of cloud computing", National Institute of Standards and Technology 53, 2011.

[22] Metzger, C., T. Reitz, and J. Villar, Cloud Computing, Carl Hanser Verlag, München, 2011.

[23] Morgan, L., and K. Conboy, "Factors Affecting The Adoption Of Cloud Computing: An Exploratory Study", ECIS 2013 Proceedings, 2013.

[24] Münzl, G., M. Pauly, and M. Reti, Cloud Computing als neue Herausforderung für Management und IT, Springer Vieweg, Berlin, Heidelberg, 2015.

[25] Ngai, E.W.T., T.C.E. Cheng, and S.S.M. Ho, "Critical success factors of web-based supply-chain management systems", Prod. Plann. \& Control 15(6), 2004, pp. 622-630.

[26] Ram, J., and D. Corkindale, "How 'critical' are the critical success factors (CSFs)?: Examining the role of CSFs for ERP”, Busin. Proc. Mngt Jour. 20(1), 2014, pp. 151-174.
[27] Recker, J., Scientific Research in Information Systems, Springer, Berlin Heidelberg, 2013.

[28] Remus, U., "Critical success factors for implementing enterprise portals", Busin. Proc. Mngt Jour. 13(4), 2007, pp. $538-552$.

[29] Repschläger, J., and R. Zarnekow, Erfolgskritische Faktoren und Kundensegmente im Cloud Computing, TU Berlin, Berlin, 2012.

[30] Rockart, J.F., "Chief Executives Define Their Own Data Needs", Harvard business review 57, 1979, pp. 81-93.

[31] Rodriguez-Repiso, L., R. Setchi, and J.L. Salmeron, "Modelling IT projects success: Emerging methodologies reviewed", Technovation 27(10), 2007, pp. 582-594.

[32] Schirm, N., T. Frank, M. Henkel, and F. Bensberg, "Erfolgsfaktoren cloudbasierter Business Intelligence Lösungen”, WI 2015 Proceedings, 2015.

[33] Şener, U., E. Gökalp, and P.E. Eren, "Cloud-Based Enterprise Information Systems: Determinants of Adoption in the Context of Organizations", In G. Dregvaite and R. Damasevicius, eds., Information and Software Technologies. Springer, Cham, 2016, 53-66.

[34] Sharma, R.M., "The impact of virtualization in cloud computing", International Journal of Recent Development in Engineering and Technology 3(1), 2014, pp. 197-202.

[35] Shawish, A., and M. Salama, "Cloud Computing: Paradigms and Technologies", In F. Xhafa and N. Bessis, eds., Inter-cooperative Collective Intelligence: Techniques and Applications. Springer, Berlin, Heidelberg, 2014, 39-67.

[36] Soliman, F., "Evaluation of Cloud System Success Factors in Supply-Demand Chains", In F. Soliman, ed., Business Transformation and Sustainability through Cloud System Implementation. IGI Global, Hershey, PA, USA, 2015, 90-104.

[37] Somers, T.M., and K. Nelson, "The impact of critical success factors across the stages of enterprise resource planning implementations”, HICSS 2001 Proc., (2001).

[38] de Sousa, J.M.E., Definition and analysis of critical success factors for ERP implementation projects, Barcelona, 2004.

[39] Vehlow, M., and C. Golkowsky, Cloud Computing Navigation in der Wolke, PricewaterhouseCoopers, 2011.

[40] Vehlow, M., and K.-F. Thier, Cloud Governance in Deutschland, PricewaterhouseCoopers, 2015.

[41] Venkatraman, R., and S. Venkatraman, "Web-Based Services", In Information Resources Management Association, ed., Cloud Adoption in Enterprises. IGI Global, Hershey, USA, 2016, 1848-1872.

[42] Venters, W., and E.A. Whitley, "A critical review of cloud computing: researching desires and realities", Journal of Information Technology 27(3), 2012, pp. 179-197.

[43] Webster, J., and R.T. Watson, "Analyzing the Past to Prepare for the Future: Writing a Literature Review", MIS Quarterly 26(2), 2002, pp. 13-23.

[44] Winkler, T.J., and C.V. Brown, "Horizontal Allocation of Decision Rights for On-Premise Applications and Software-as-a-Service", Journal of Management Information Systems 30(3), 2014, pp. 13-48.

[45] Yang, H., and M. Tate, "A Descriptive Literature Review and Classification of Cloud Computing Research.", Communications of the AIS 31(2), 2012, pp. 35-60. 